\title{
CORRELATION BETWEEN RAILWAY SUBGRADE SETTLEMENT AND SHIELD TUNNELING CONSTRUCTION
}

\author{
Liu Liu*1, Qian Shen ${ }^{2}$, Yinghua Zhao ${ }^{3}$ \\ 1,2,3Hebei Jiaotong Vocational and Technical College, Shijiazhuang, Hebei 050091, China \\ ll2liu@aliyun.com
}

\begin{abstract}
With the rapid development of cities, relevant rail transit construction also develops at a high speed. However, the construction space above the ground is limited, and rail transit covering large construction area is often constructed underground, so the shield tunnel is bound to be used for the underground rail transit construction. In this study, the influence of shield tunneling construction on railway subgrade was analyzed using numerical simulation method, and the influence of stratum reinforcement measures on subgrade in construction process was also analyzed. The results showed that shield tunneling construction could cause subgrade settlement and the influence became larger and larger with the proceeding of project. When the left line was completed, the maximum settlement point was located above the center line of the left tunnel, and the settlement was $7.506 \mathrm{~mm}$. When the right line was completed, the maximum settlement point was located above the central line of the two tunnels, and the settlement was $9.970 \mathrm{~mm}$. Grouting reinforcement measures for stratum around the tunnel could significantly reduce the settlement; the maximum settlement decreased by $62.84 \%$ when the left line was completed and $58.65 \%$ when the right line was completed. To sum up, shield tunneling construction of railway will cause subgrade settlement, and stratum grouting reinforcement measures can significantly reduce subgrade settlement.
\end{abstract}

Keywords: Railway, Shield Tunneling, Simulation Analysis, Settlement.

\section{Introduction}

With the rapid development of urbanization, the utilization rate of space above the ground is gradually saturated, and the ground traffic is gradually difficult to meet the increasing demand of residents' traffic [1]. Therefore, the rail transit which can be built underground has become an effective solution. Shield construction is one of the main construction methods of underground light rail transportation [2]. Compared with other underground construction methods, shield construction has less impact on the environment and faster construction progress. Shield tunneling [3] has little impact on geological environment. When shield tunnel goes through the space below the existing railway, it will cause the subsidence of the existing railway subgrade, posing a potential threat to construction projects and railway traffic in operation. Shield tunneling will directly cause the ground settlement around the tunnel. After the ground subsidence, the railway subgrade and rail built on the ground will be deformed. Factors affecting stratum settlement in shield tunneling [4] include soil properties, grouting volume, pressure and time, shield driving time, etc. Moreover the relative position of the direction of shield excavation and the forward direction of existing railways will directly affect the settlement of railway subgrade. In order to reduce the influence of ground subsidence on railway subgrade, reinforcement measures are often adopted [5], including: reinforcement of foundation, reinforcement of rails, reinforcement of tunnels with D-beam and grouting reinforcement of strata around tunnels during excavation. Liang et al. [6] regarded shield tunnels as continuous Euler-Bernoulli beams and corrected based on Pasternak foundation model. A modified formula of subgrade modulus considering the influence of foundation depth on subgrade modulus was proposed. The response of tunnels was analyzed by two-stage analysis method. Comparison with three-dimensional finite element analysis and two released field measurement results suggested that the method was feasible. In the study of Cai et al. [7], the finite element model of the track-subgrade-soil was established to analyze the deformation features of the track under shield tunneling, taking the interaction between shield construction and the structures of the high-speed railway into consideration. They found that the deformation degree of rail was in direct proportion to excavation distance and the vertical deformation was larger than the horizontal deformation. Di et al. [8] analyzed the differential settlement characteristics of Nanjing Metro Line 1 after four years of line expansion operation and the reasons for the uneven settlement along the line by comparing with the geological conditions along the line and the adjacent construction 
activities and found that the uneven distribution of soft soil under the subway tunnel and the adjacent construction activities were the main reasons for the differential settlement. In this study, the influence of shield tunneling on railway subgrade in phase 1 project of $\mathrm{X}$ line in $\mathrm{XX}$ city was simulated by MIDAS/GTS software, and the influence of shield tunneling on railway subgrade before and after grouting reinforcement was analyzed and compared.

\section{Railway Subgrade Settlement}

Shield tunneling will inevitably affect the surrounding strata, which will lead to subsidence of strata, directly lead to different degrees of deformation of railway subgrade and track above strata, and have a negative impact on railway traffic operation. The top surface difference between the two rails in the railway track cannot exceed $6 \mathrm{~mm}$. If the horizontal deviation between the two rails exceeds $6 \mathrm{~mm}$ when the length of the rail is lower than $18 \mathrm{~m}$, the train derailment accident is very likely to happen. When the length of rail is lower than $10 \mathrm{~m}$, the deviation between the front and back side of the track cannot exceed $6 \mathrm{~mm}$. The location relationship between shield tunnels and existing railways is usually orthogonal, and the ground surface near the orthogonal location will have obvious settlement. Therefore, the settlement of subgrade caused by ground settlement should be taken into account in the design of shield tunnels.

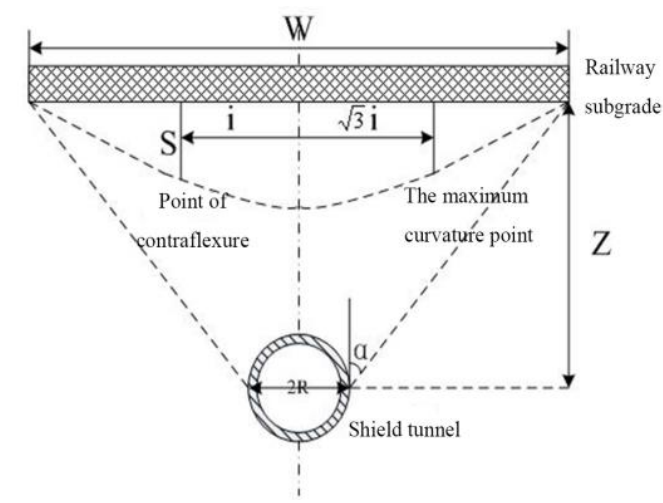

Figure 1: The schematic drawing of railway subgrade settlement

The subgrade model of railway settlement is shown in Figure 1. The bold horizontal axis with arrows represents the road surface where the railway locates, and the circle below represents the shield tunnel. The impact of ground surface settlement is usually calculated using Peck formula [9]:

$$
S=S_{\max } e^{-\frac{x^{2}}{2 i^{2}}}
$$

where $x$ stands for the distance with the center line of the construction tunnel, $S$ stands for the settlement amount of ground surface which is $x$ away from the center line, $S_{\max }$ stands for the maximum settlement amount of ground surface, and $i$ stands for the width coefficient of subsider. The expression of $i$ [10] is:

$$
i=(H+R) / \sqrt{2 \pi} \tan \left(45-\frac{\varphi}{2}\right)
$$

where $H$ stands for the thickness of soil layer on the road where the existing railway, $R$ stands for the external radius of tunnel, and $\varphi$ stands for internal friction angle.

$W$ in Figure 1 stands for the width of the subsider. The relationship between the width of the subsider and width coefficient was calculated using Mohr-Coulomb yield criterion [11], $i=\frac{W}{5}$, then the relationship between the maximum settlement amount and settlement volume [12] is:

$$
V=\sqrt{2 \pi} S_{\max } i
$$

where $V$ stands for the volume of subsider, which can be approximately considered as ground loss.

\section{Instance Analysis}

\section{Project profile}

Phase 1 project of Metro Line $\mathrm{X}$ in $\mathrm{XX}$ city is $31.145 \mathrm{~km}$ long, including 22 stations, all of which are underground. There are 198 locations with risk level higher than four in the whole route, including 45 houses above tunnels, 7 railways above tunnels and 16 bridges above tunnels.

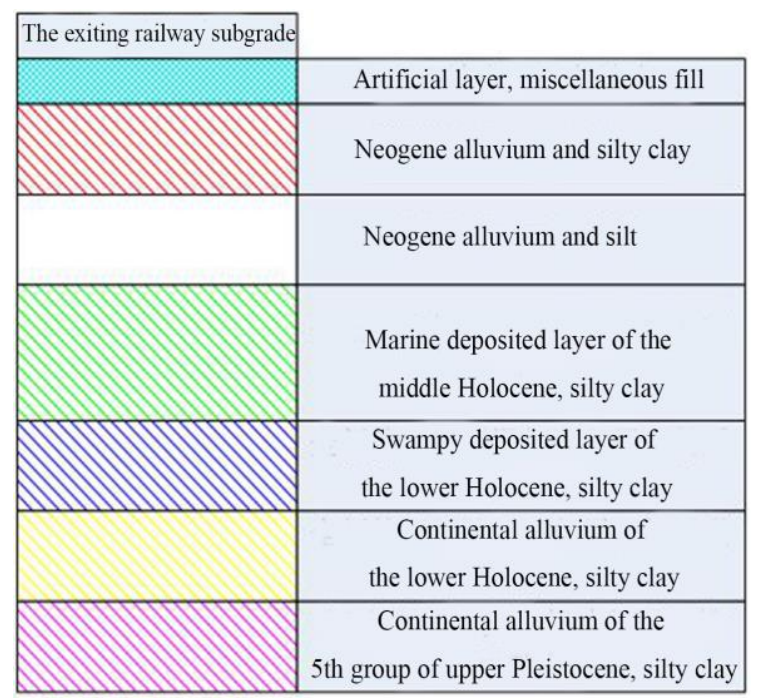

Figure 2: Engineering geologic profile

As shown in Figure 2, the geology of the metro construction site is divided into continental alluvium of the 5th group of upper Pleistocene, continental alluvium of the lower Holocene, swampy deposited layer of the lower Holocene, marine deposited layer of the middle Holocene, Neogene alluvium and artificial fill stratum 
by the age of formation. Strata except the artificial fill layer which was miscellaneous fill layer and the substratum of the Neogene alluvium which was silt layer are all silty clay layer. The tunnels of the metro project were located in the marine deposited layer of the lower Holocene [13].

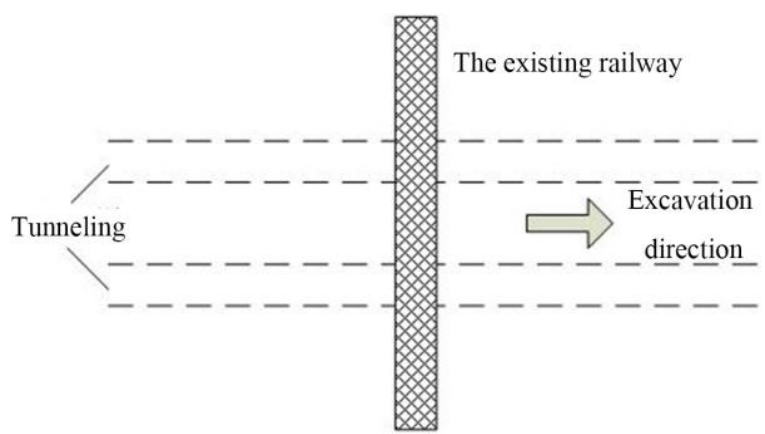

Figure 3: The plan view of the relative position of the existing railway and tunnels

As shown in Figure 3, the railway with shield tunnels was a passenger railway. The shortest distance between the top of the tunnel and the railway subgrade was $19.458 \mathrm{~m}$. The railway and the tunnel was in an angle of $90^{\circ}$. The distance between the two tunnels is 15.000 M. The excavation method was earth pressure balance shield tunneling. The right line of the forward direction was excavated first, and then the other side was excavated.

\section{Mode establishment}

- Numerical model

The model of stratum, railway subgrade, rail, segment and grouting layer were constructed using MIDAS/GTS software [14]. The material property of the stratum model was set as elastic-plastic material and the other models were set as elastic material. The model was set as $100 \mathrm{~m}$ long, $90 \mathrm{~m}$ wide and 60 $\mathrm{m}$ high. The rail specification was $55 \mathrm{~kg} / \mathrm{m}$, and the track gauge was $1.435 \mathrm{~m}$. Vertical constrained displacement was set at the bottom of the model.

\section{- Parameter selection}

The strata and structural parameters which were needed in the simulation of railway subgrade settlement are shown in Table 1.

\begin{tabular}{|c|c|c|c|c|c|}
\hline Item & $\begin{array}{l}\text { Unit weight } \\
/\left(\mathrm{kg} / \mathrm{m}^{3}\right)\end{array}$ & $\begin{array}{l}\text { Elasticity } \\
\text { modulus /MPa }\end{array}$ & $\begin{array}{l}\text { Poisson's } \\
\text { ratio }\end{array}$ & $\begin{array}{l}\text { Internal friction } \\
\text { angle } /^{\circ}\end{array}$ & $\begin{array}{l}\text { Cohesive } \\
\text { force } / \mathrm{kPa}\end{array}$ \\
\hline Miscellaneous fill & 18.5 & 12 & 0.5 & 5 & 14 \\
\hline Silty clay & 19.4 & 34 & 0.36 & 15 & 11 \\
\hline Silt & 19.1 & 55 & 0.28 & 31 & 0 \\
\hline Railway subgrade & 2500 & 67 & 0.3 & l & l \\
\hline Rail & 7810 & 2150 & 0.3 & I & 1 \\
\hline Segment & 23 & 28735 & 0.3 & I & I \\
\hline $\begin{array}{l}\text { Grouting layer } \\
\text { (liquid) }\end{array}$ & 22 & 0.3 & 0.3 & / & / \\
\hline $\begin{array}{l}\text { Grouting layer } \\
\text { (solid) }\end{array}$ & 22 & 410 & 0.3 & / & / \\
\hline
\end{tabular}

\section{- Construction simulation}

The tunnel excavation method of the whole excavation project was earth pressure balance. There were three processes. The concrete simulation steps in MIDAS/GTS software after proper simplification were as follows. A soil mass whose step length was equal to two segments was excavated. The shield shell was activated, and an ejection force of $210 \mathrm{kPa}$ on the tunnel face was simulated. Then the activated shield shell was passivated, the segment was activated, and an ejection force of $3600 \mathrm{kPa}$ in front of the segment was simulated. The shield shell outside the segment was activated, the shield shell property was replaced with the grouting property, and an uniform load of $320 \mathrm{kPa}$ was simulated in the space of the segment and excavation area.

Double-line distributed construction mode was used [15]. The left line was excavated firstly, and then the right line was excavated. The tunnel was $16 \mathrm{~m}$ below the ground. When the reinforcement measure was simulated, the soil layer within $2 \mathrm{~m}$ of the upper cross section of the tunnel was given soil reinforcement property.

\section{- Calculation results}

As shown in Figure 4, L represents the excavation face of the left tunnel, $\mathrm{R}$ represents the excavation face of the right tunnel, and 0 represents the center of the two tunnels. Abscissa X of the center line of the left tunnel was $-7.5 \mathrm{~m}$, and abscissa $\mathrm{X}$ of the center line of the right tunnel was $7.5 \mathrm{~m}$. Shield tunneling was bound to affect the surrounding soil layer, which might lead to different degrees of settlement of the railway subgrade above. The distribution characteristics of the settlement curve in Figure 4 were the same as Gauss curve, and the settlement degree of the subgrade above the tunnel was more obvious than other soil layers. When the tunneling of the left line was completed, the maximum settlement point of the subgrade was right above the center line of the left tunnel, and the maximum settlement was 7.506 $\mathrm{mm}$. After the shield construction of the right tunnel, the maximum settlement value of the subgrade continued to increase, and the maximum settlement point gradually shifted to the right tunnel. 
When the excavation surface of the right tunnel passed through the existing railway for 2 meters, the change of the maximum settlement point of the subgrade was relatively sudden, and finally the maximum settlement point of the subgrade was stable at the center of the two tunnels; at that time the tunneling of the right tunnel was completed, and the maximum settlement was $9.970 \mathrm{~mm}$.

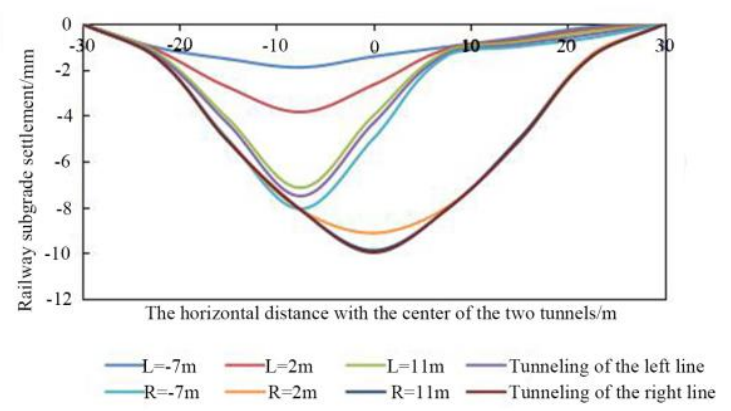

Figure 4: The settlement of the railway subgrade in the process of railway tunneling

As shown in Figure 5, whether the stratum was reinforced or not, the settlement curves of the railway subgrade were almost the same when the tunneling of the left and right tunnels completed: when the tunneling of the left tunnel was completed, the maximum settlement point of the railway subgrade was right above the left tunnel; when the tunneling of the right tunnel was completed, the maximum settlement point of the subgrade shifted to the right and was right above the center of the two tunnels. The difference of the subgrade settlement distribution curve between the reinforced and unreinforced subgrade was that the settlement amplitude of the railway subgrade was greatly reduced after stratum reinforcement.

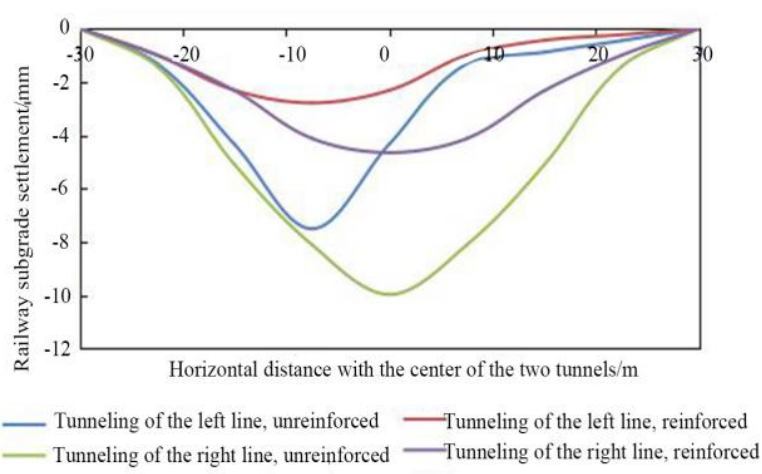

Figure 5: The curve of settlement of the reinforced and reinforced subgrade in the tunneling of the left and right tunneling

As shown in Table 2, when the tunneling of the left line was completed, the maximum settlement value of railway subgrade in the unreinforced stratum was 7.506 $\mathrm{mm}$ and the maximum settlement area located in the site where was above the center of the left runnel and near the railway subgrade; the maximum settlement value of the subgrade in the reinforced stratum was $2.789 \mathrm{~mm}$, and the maximum settlement area was located above the center line of the left tunnel and near the excavation surface of the tunnel.

When the tunneling of the right line was completed, the maximum settlement value of the railway subgrade in the unreinforced stratum was $9.970 \mathrm{~mm}$, and the maximum settlement area was above the center line of the two tunnels and near the railway subgrade; the maximum settlement value of the railway subgrade in the reinforced stratum was $4.123 \mathrm{~mm}$, and the maximum settlement area was located above the center line of the two tunnels near the excavation face of the tunnel.

\begin{tabular}{|l|c|l|}
\multicolumn{3}{|c}{ Table 2 The statistics of the railway subgrade and stratum displacement } \\
\hline Engineering condition & $\begin{array}{l}\text { The maximum } \\
\text { settlement value/mm }\end{array}$ & $\begin{array}{l}\text { The position of the maximum settlement point of the } \\
\text { stratum }\end{array}$ \\
\hline $\begin{array}{l}\text { The left line was tunneled and the } \\
\text { stratum was not reinforced }\end{array}$ & 7.506 & $\begin{array}{l}\text { Horizontally, locating at the center line of the left } \\
\text { tunnel; vertically, locating near the railway subgrade }\end{array}$ \\
\hline $\begin{array}{l}\text { The left line was tunneled and the } \\
\text { stratum was reinforced }\end{array}$ & 2.789 & $\begin{array}{l}\text { Horizontally, locating at the center line of the left } \\
\text { tunnel; vertically, locating near the excavation face of } \\
\text { the tunnel }\end{array}$ \\
\hline $\begin{array}{l}\text { The right line was tunneled and } \\
\text { the stratum was not reinforced }\end{array}$ & 9.970 & $\begin{array}{l}\text { Horizontally, locating at the center line of the two } \\
\text { tunnels; vertically, locating near the railway subgrade }\end{array}$ \\
\hline $\begin{array}{l}\text { The right line was tunneled and } \\
\text { the stratum was reinforced }\end{array}$ & 4.123 & $\begin{array}{l}\text { Horizontally, locating at the center line of the two } \\
\text { tunnels; vertically, locating near the excavation face } \\
\text { of the tunnel }\end{array}$ \\
\hline
\end{tabular}

It was found from the data in Table 2 and curves in Figure 5 that the railway subgrade settlement caused by shield tunneling was reduced after the reinforcement of strata, which was because that the sedimental stratum lowered from the site near the railway subgrade to the site near the excavation face. Therefore grouting reinforcement on stratum can effectively reduce subgrade and stratum displacement, ensuring the safe operation of railway.

\section{Conclusion}

In this study, the influence of shield tunneling on railway subgrade in phase 1 project of Line $\mathrm{X}$ in $\mathrm{XX}$ city was simulated by MIDAS/GTS software, and the influence of shield tunneling on railway subgrade before and after grouting reinforcement was analyzed and compared. 
The results are follows. Shield tunneling under railway caused subgrade settlement. With the proceeding of shield tunneling, the settlement value and influence range of subgrade increased. When the tunneling of the left line was completed, the large settlement value was $7.506 \mathrm{~mm}$, which was located above the center line of the left tunnel. When the tunneling of the right tunnel started, the maximum settlement point shifted to the right, and the maximum settlement position was 9.970 $\mathrm{mm}$ when the tunneling was completed, which was located above the center line of the two tunnels. Grouting was used to reinforce the stratum, and the settlement of the subgrade decreased greatly. The maximum settlement of the subgrade with the reinforced stratum was $2.789 \mathrm{~mm}$ when the tunneling of the left line was completed, decreased by $62.84 \%$, and was $4.123 \mathrm{~mm}$ when the tunneling of the right line was completed, decreased by $58.65 \%$.

\section{References}

[1] $\mathrm{Li} \mathrm{B}, \mathrm{Wu} \mathrm{L}, \mathrm{Xu} \mathrm{C}$, et al. "The Detection of the Boulders in Metro Tunneling in Granite Strata Using a Shield Tunneling Method and a New Method of Coping with Boulders." Geotechnical \& Geological Engineering, 2016, 34(4):1155-1169.

[2] Huang H, Gong W, Khoshnevisan S, et al. "Simplified procedure for finite element analysis of the longitudinal performance of shield tunnels considering spatial soil variability in longitudinal direction." Computers \& Geotechnics, 2015, 64:132-145.

[3] Zhou S, Xiao P J, Di $H$, et al. "Differential settlement remediation for a new shield metro tunnel in s." Revue Canadienne De Géotechnique, 2018.

[4] Wen X, Zhi D, Qin J, et al. "Influence of Shield Tunnelling in Soft Soil on Adjacent Buildings with Shallow Foundations." Modern Tunnelling Technology, 2017, 54(2):106-113.

[5] Huang X, Zhu Y, Zhang Z, et al. "Mechanical behaviour of segmental lining of a subrectangular shield tunnel under self-weight." Tunnelling \& Underground Space Technology, 2018, 74:131-144.
[6] Liang R, Wu W, Yu F, et al. "Simplified method for evaluating shield tunnel deformation due to adjacent excavation." Tunnelling \& Underground Space Technology, 2018, 71:94105.

[7] Cai XP, Cai XH, Tan SY, et al. "Research on the influence of under-passing shield tunnel construction on the track structures of highspeed railway." Journal of Railway Engineering Society, 2016.

[8] Di HG, Zhou SH, Gong QM, et al. "Differential settlement of metro tunnels and its zonal control in soft deposits." Chinese Journal of Geotechnical Engineering, 2015, 37:74-79.

[9] Huang Q, Huang H, Ye B, et al. "Evaluation of train-induced settlement for metro tunnel in saturated clay based on an elastoplastic constitutive model." Underground Space, 2017.

[10] Zhu C, Li N. "Prediction and analysis of surface settlement due to shield tunneling for Xi'an Metro." Canadian Geotechnical Journal, 2017, 54(4).

[11] Huang Q, Huang H W, Ye B, et al. "Dynamic response and long-term settlement of a metro tunnel in saturated clay due to moving train load." Soils \& Foundations, 2017, 57(6):10591075.

[12] Novozhenin SU, Vystrchil MG. "New Method of Surface Settlement Prediction for Saintpetersburg Metro Escalator Tunnels Excavated by EPB TBM." Procedia Engineering, 2016, 150:2266-2271.

[13] Zheng XR. "Determination of Main Influence Angle of Ground Settlement Caused by Xi"an Metro Tunnel Construction." Advanced Materials Research, 2015, 1065-1069:327-332.

[14] Qiu M, Yang G, Wu ZQ, et al. "Distribution Laws of Surface Settlement Induced by Shield Construction of Twin-Tube Metro Tunnels." Modern Tunnelling Technology, 2017, 54(2):96-105.

[15] $\mathrm{Hu}$ SM. 'Deformation distribution control of ground settlement for cavern-pile station in Beijing metro." Journal of Beijing Jiaotong University, 2016. 